\title{
Youth Related Issues in the Saudi Press Coinciding with the "Arab Spring": A 2-Month Monitoring and Analysis of Press Coverage
}

\author{
Nizar H. Al Salih and Kadhem A. Al Ghoul
}

\begin{abstract}
This study aimed at monitoring and analyzing the press coverage of Saudi youth-related issues in all Saudi daily papers in Arabic. It was conducted following the victory of the revolutions in Tunisia, Egypt, Libya, and Yemen while in Syria it is still ongoing. In the study (4514) issues were analyzed and classified into (9) main issues during (59) days. The scope of this study is the monitoring of the 12 Arabic Saudi daily papers issued during the period from $02 / 06 / 2011$ to $30 / 07 / 2011$. The study findings indicated that the press coverage percentage of: Education issues was $(\mathbf{2 2 . 4 0 \% )}$, Employment (17.08\%), Security and Political issues $(\mathbf{1 5 . 0 0 \%})$. Whereas the Citizenship issues $(5.49 \%)$, and the Information and Culture issues was $(4.70 \%)$. All findings and recommendations of the study included.
\end{abstract}

Index Terms-Arab spring, press coverage, Saudi youth related issues, themes.

\section{INTRODUCTION}

Based on Statistics and Information in the Ministry of Economy and Planning [1], of the Saudi Population and Housing Census released by the Central Department Of Statistics and Information, the Saudi youth (15-29 yrs.) represented (29.9\%). Since the Arab world particularly the North African countries witnessed, during the previous two years, a lot of sociological and political changes with positive and negative repercussions felt in most of the other Arab countries. The Kingdom of Saudi Arabia is no exception, being the heart of the Arab and Islamic world found that it was imperative to monitor the changes and counteract the causes that led to the uprisings and social upheaval sweeping some of the Arab countries in the region. With the above in mind, the two researchers had monitored and analyzed the articles that appeared on the various (12) Arabic newspapers issued daily in the Kingdom of Saudi Arabia for a 2-month period, after almost a year from the start of the Tunisian uprising [2], with the intention of identifying the impact of such uprisings on the high youth population in the Kingdom of Saudi Arabia.

\section{The ARAB SPRING: Global Perspectives}

Arab Spring Phenomenon - started from Tunisia in the summer of 2010. It was due to various reasons that differ

Manuscript received September 19, 2013; revised November 25, 2013. This work was supported in part by King Saud University.

The authors are with the National Center for Youth Studies, King Saud University, Saudi Arabia (e-mail: welcomey4@hotmail.com, kadhem_1977@yahoo.com). from one country to another, however, there was a common reason behind all these uprisings and resentment - feeling injustice was served to all except the ruling class, their relatives and acquaintances who had more than what they really hoped for; you can call that favoritism, cronyism and nepotism. Moving to what various writers and analysts cited as the causes and reasons behind the different uprisings, each from his own perspective, we found that:

Reference [2] had drawn a comparison between the Arab Spring and the Eastern Europe 1989 revolutions in his article "Whither the Arab Spring? 1989 or 1848?", and arrived at the conclusion that "the importance of potential Arab democratic transitions will face more substantial obstacles than Eastern Europe did in 1989. Those obstacles include the intense securitization of the Middle East, the absence of agreed upon models for future polities and economies, the residual power of authoritarian systems, and the limited capacities of newly emerging political and civil societies. The poster children of the Arab Spring, Tunisia and Egypt, are not well equipped to imitate the success of Eastern European countries. The Arab Spring of 2011 may thus be more akin to the 1848 failed revolutions than to the democratic transitions set in motion by the crumbling of the Soviet Union in 1989".

Reference [3] discussed in their study - "Global Warming and the Arab Spring" - the important role played by the climate change which had its own impact on the events that did lead to today's Arab Spring revolutions in the sense that climate change had, to a certain point, influenced global food shortages and sharp increases in food prices which triggered popular unrest and riots that eventually resulted in regime changes.

Whereas, however, [4] highlighted the views held by Iranian thinkers regarding the Arab Spring that - contrary to what observers viewed the uprisings engulfing most of the Arab countries as a positive sign of freedom and democratic change - these uprising as positive Islamic-inspired revolutions in line with the Iranian revolution. However, at the same time they looked at the Syrian one from a different perspective - as an illegitimate riots by factions opposing the Syrian regime and government instigated by the western powers.

Reference [5] wrote about " Obama and the 'Arab Spring': desire, hope and the manufacture of disappointment". That during the run up to the $(2007 / 2008)$ USA election and the few following the election months, 'Obama' represented hope for most of the people in the world, expecting him to affect important global changes. But, this hope turned to disappointment, after the strong grip of the global financial crisis which had its impact on the various individuals in the 
whole world, people saw now apparent breakthrough and no hope of success in tackling this crisis.

Whereas [6], looked at the Arab Spring from a different perspective, "the International Dimension of the Arab Spring", mentioning that the Arab spring would create sovereign Arab states, that do not passively follow the west namely USA. Hence the west in general and the USA foreign strategies and policies towards the Middle East should be reconsidered.

Moreover, [7] confirmed that significant change is unlikely soon. However, at the same time she was interested in the scientific improvement and advancement in the Arab and Middle Eastern countries after attaining the political and economic stability in a time space of about 25 years. She further mentioned the fact that the Islamic religion demanded people to explore all the nooks and corners in the world.

Finally, [8], wrote a paper about "Problematizing Arab Youth: Generational Narratives of Systemic Failure that Arab youth have proved to be an engine for long-awaited political change in the region". In this paper Murphya suggested that owing to the youth exclusion, suppression and marginalization by their own rulers and the continuous failures in all political, economic and social fields, the Arab youth found no way to express themselves other than protests and demonstrations against their regimes.

However, these aforementioned conditions do not apply to some countries, namely the Kingdom of Saudi Arabia, which has enjoyed stability in all fields.

The kingdom of Saudi Arabia (KSA) is witnessing a remarkable media explosion reflected by the quantitative and qualitative development in the local media institutions, and in the increasing awareness regarding the significance of the media. Despite the growing importance of youth, the scientific and applied specialized media studies and researches regarding youth-related issues in the KSA have not given the due care they deserve. The studies and researches conducted so far in this area may be considered individual initiatives and endeavors using the humble assistance rendered in study and research centers and units in some Saudi universities with regard to master and doctorate theses. Given this situation, the current study has emerged to cover the youth related issues (YRI) in one form of the print media - the KSA daily newspapers. The aim of this study is to monitor and analyze the extent of the YRI press coverage on daily basis, on monthly basis, on each of the newspapers basis, on newspaper issue category basis. In addition to monitoring and analyzing the YRI coverage on the basis of size, general topic and opportunities and threats basis, YRI on significance basis, trend basis, and on the YRI gender basis. The significance of this study emanates from the importance of the age category under study - youth, to cover their issues and concerns in the Saudi daily papers through the thinkers' and writers' opinions and the youth opinions with regard to their own concerns.

Reference [9] described the press as a social construction i.e. it is subject to continuous innovation and improvement through interactive actions - the social interaction that slowly push it into the democratic horizon, and the economic interactions that supports the press, the cultural interaction which is knowledge productive and the various media means which cover the day to day actions in the society. He adds blogs to the print media. [9] defined Journalism as "changing the perspective to have a full picture of the knowledge horizon" which is a limited institutional area that is governed by its code of ethics. A professional journalist loses his independence for his link with the employer, and suffers from his own Self-censorship and to comply with the responsibilities towards his institution and the society. The journalism is full of details and elaboration and its objective and contractual style. Writing is to reproduce the typical predominant mode of writing. Print media materials should vigorously stand alone in the absence of it strong echo. The controversial writing is very rare if it ever exists. The text is closed and is controlled by its writer who is under the influence of the institution over him despite his vast knowledge. Some print media materials are published in series and episodes; however, most of the materials are close-end. The print media materials are classified into two: the significance seen by the newspaper and the issues and topics to be distributed among the sections. Any newspaper seeks to have a scoop. It is normal that readers are of various and different trends and as such the number of readers of each particular topic is hard to be known. Newspaper' sales data will take a long time to arrive at. Proofreading and editing are the job a specialist in this field that is done before publishing the paper. Print media is less transparent as it sometimes, does not disclose the source of information. The exact stance of the journalist is concealed by that of his employer/institution. Each and every material is categorized according to the issue covered. Even then, the newspaper maintains its old typical style including reportage. In the end media institutions wage a fierce competition among them as each of them is an investment project that seeks profitability even if they render the same media contents.

Reference [9], arrived at the fact that the future of journalism should be preceded by to have a media means that produce concepts that identifies current changes and predicts future ones in the media and communication arena. In addition to the chronological order of events, so that any discontinuity or lapse will be quickly detected. The change arrived at by this study is from opinion media perspective to news and finally to communication media perspectives. It is the deep change that affects all areas of journalism: economic construction, profession and contents, types of writing, production and functions and the relationship with readers. The journalism is not a given thing that does not change. It is a renewable team innovation that clearly detects the influential factors in the development of journalism and all new media means within a dynamic vision of the socioeconomic, cultural, technological and ecological change in the different societies. The perspective of the development of journalism warns us of the risk of general speech apart from the impact of the new media means (e.g. blogs) on print media. Blogs do not have the same impact on the classical media in all societies. The relation between the blogs and the classical media means in the Arab world is a practical proof of that.

Reference [10], spoke about the university journalism and its administrative and organizational aspects in the KSA; how it functions. He arrived at the conclusion that most of the 
newspapers suffer from the weak appreciation of those in charge at the universities for the mission of such newspapers. University newspapers focus on the activities, contributions and scientific theses in addition to academic university achievements which render the newspapers a top-to-bottom organization without interaction from the other university students and audience.

Reference [11], in his Study focused on the methods and performance appraisal used in the Saudi media institutions, and he concluded that such methods lack the clear concept understanding and implementation of scientific measures to appraise and encourage journalists. This leads to a state of dissatisfaction and displeasure on the part of the Saudi journalists.

Reference [12], arrived at the fact that the computers share of the students usage and viewing with regard to products' commercials in the university newspaper. Advertisement along with the books and stationeries have the greatest share of follow-up and concern. The medium concern share goes to mobiles and phone sets and accessories thereof in addition to autos, food items and beverage. However, real estate, furniture concern was pushed back to a relative minimum. The most followed up and covered services list was: institutes of computer training and language teaching institutes, employment and jobs, university students' services ; $62 \%$ out of a selected representing sample indicated that they follow up these 3 services. These 3 services came at the top of the list followed by internet services, prepaid telephone cards then bank services, transport, flights, tourism, hospitals, medical service, hotels and furnished apartments services. In the very end of the list comes the general repair and maintenance services.

Reference [13] referred to the concern of the press studies about the Citizen journalism or the grassroots journalism, the concept raised up by Dan Gillmor in 2004. Based on this, a lot of researches were conducted asking people to pay more attention to these new types and shapes of journalism and to effect profound change in the media practices being used in traditional media means; journalists should stop clinging to their unlimited authority in all the process of media contents production allowing the users to participate in some of these processes (Paulussen,Ugill,2008); and that the journalist should stop; and that the press should avoid the traditional image of the news and information flow in an effort to take in the contents provided by the new media coupled with the possibility of increasing the area of mutual benefit between the traditional and electronic new media means; reinforcing the cooperation between the professional journalists and amateur users (Paulussen et al. 2007). Other studies emphasized the importance of the development of citizen media concept and linked it to the public journalism concept. In an effort to establish a mutual relationship between the journalists and audience. The development of this concept has been assisted by the modern technological inventions which facilitated the interaction with the audience who contribute in the creation of the contents and in furthering the dialogue between the two parties to the extent that any citizen has a role to play in creating knowledge feedback and expressing himself in a clear understandable way. This kind of interactive communication has created new in-depth means in creating and establishing knowledge industry. It lays special emphasis on cultural identity for the local communities and the democratic participation of all levels. It is an ongoing process of dialogue, education between the individuals in the society.

Reference [13] also referred to Pettit, j. et al. (2009), Harcup, T.(2005) and Ramaprasad and Hamdy (2006) study about the functions of the Egyptian journalists which are: maintain and sustain democracy, support Arabism and society values, support government policies, and providing the citizens with entertainment. The study found that the Egyptian journalists maintain that the most outstanding function is the support of society values and the Arabism.

Reference [14] indicated that most Saudi youth highly prefer Okaz, Arriyadiyah, and Madina newspapers. As for the topics and issues preferred by them we find the status quo political events followed by the youth related issues. With regard to the questions of the extent of the Saudi youth satisfaction vis-à-vis their issues coverage, some of them were "Fully Satisfied" or "to some degree". However, more than $2 / 3$ rd of youth were not satisfied. It was evident that the non-reliability and the superficial tackling of issues are the main sources that contributed to this dissatisfaction.

Saudi youth claim that Saudi daily papers focus mostly on sports, education and scientific issues. Youth saw that the general issues and topics covered in the daily papers were terror and violence issues. [15] cited some reasons for the adolescents to keep away from print media: adolescents prefer other media means therefore most of them do not read newspapers; the newspapers have no credibility for them. However, the newspapers' contribution to favorably utilized leisure time resulted in more adolescent readership, plus the fact that newspapers represent an entertainment source for some; in addition to the fact that families subscribe or at least purchase some daily papers and the adolescents found them at their disposal, in addition press release was the most attractive of all for adolescents plus the caricature, followed by the investigations, articles and the press photos and the press interviews.

\section{Methodology AND PROCEDURES}

\section{A. Study Problem}

In light of what the Middle East region is witnessing with regard to the political upheavals and changes known as the "Arab Spring" and as the force behind all this is the youth force, this study has been conducted to monitor the way the Saudi Arabic daily papers have covered the youth related issues, given the unstable political climate in the current political state of affairs. This is happening concurrently with the ongoing revolt in Syria and the culmination of other revolts in Tunisia, Egypt, Libya and Yemen.

\section{B. Study Objectives}

- Monitoring and analyzing of the youth-related issues press coverage during the days of the week.

- Monitoring and analyzing of the youth-related issues press coverage based on the newspaper art category.

- Monitoring and analyzing the coverage extent of youth related issues per issue size. 
- Monitoring and analyzing the coverage extent of youth related issues per the general topic/issue.

- Monitoring and analyzing the coverage extent of youth related issues per opportunities and threats.

\section{Study Significance}

The significance of this study emanates from the significance of the population studied - youth and related issues in the Arabic Saudi daily papers through monitoring analyzing the views of writers and thinkers at a time of political upheavals and changes in the Middle East widely known as the "Arab Spring".

\section{Study Scope}

The scope of this study is the monitoring of the 12 Arabic Saudi daily papers issued in the KSA during the period of month 7 and 8 of the 1432 Hijri Calendar corresponding to the period 02/06/2011 to 30/07/2011 Gregorian Calendar.

\section{E. Study Methodology}

The content analysis is the methodology followed in this study because it is the most appropriate methodology in the media studies, which aims to objectively and quantitatively describe the content of one of the media and communication material.

\section{F. Study Procedures}

The media coverage of the Saudi youth related issues was closely monitored during the period June 3rd to July 31st 2012G (i.e. month 7 and 8 of 1432 Hijri Calendar), of the 12 online Saudi Arabic daily papers: Alriyadh, Aljazirah, Okaz, Almadinah, Alwatan, Alyaum, Alnadwah, Albilad, Alsharq Alawsat, Aleqtisadiah, Shams and Alhayat. The total issues covered were 4514 throughout the 59 days from June 3 rd to July 31 st $2012 \mathrm{G}$ (corresponding to month 7 and 8 of the 1432 Hijri Calendar) with an average daily coverage of approximately 77 issues. A form has been designed for the encoding of issues with respect to the study variables, levels, categories, themes where frequencies and percentages were computed using the SPSS statistics program. Finally tables were analyzed and commented on arriving at a number of findings based on the study results.

\section{G. Content Criteria}

In order to arrive at quantitative findings through objective way based on the content analysis methodology used in the study, the following criteria were observed: Issue was considered analysis unit, whereas frequency was considered measurement unit.

The results and findings were recorded in the special form including the study variables.

Implementation procedures: To conduct a content analysis, the following procedures and steps were taken:

Youth related issues were considered one unit of the study.

Issues contents were carefully and thoroughly scrutinized to identify the youth related way of thinking contained in each and every issue.

Issues were classified into main issues sections. Then each issue was separately read to identify the value of its contents.

The youth related issue is considered an analysis unit.

The total youth related issues covered during the period were 4514 issues.

A form has been designed to analyze the contents of all main youth related issues.

Content analysis findings were arrived at (including frequencies and percentages).

\section{H. Study Analysis Unit Used in}

Unity of issue and frequency were used as unit of analysis.

Study Themes: The study themes were selected based on the main 7 themes of the youth national strategy prepared by the Saudi ministry of Economy and planning which are: Education and training; employment; health; information and culture; recreational activities; the proper use of leisure time; Information Technology and communication; knowledge society; citizenship; political and security; and the social themes.

\section{Study Variables, Categories and Levels}

The study contained the following variables:

- The day of the week: Saturday ....Friday.

- The type of the journalistic technique: News, Article, Interview, Report, Advertisement ...etc.

- Size of issue: long (>201 words), medium (101-200words) and short ( $<100$ words)

General Topic (issue): which included 9 topics: education \& training; Employment; Health; Information \& Culture; Recreational Activities; making best use of leisure time; IT and communication; knowledge society; citizenship; security and political issues; social issues and topics.

Opportunities \& Threats: indicators of youth opportunities, problems and crises.

\section{RESUlt AND Discussion}

Press coverage of youth related issues per the "day of the week" variable.

It was clear that the highest youth related issues' press coverage in the 12 Arabic language daily Saudi papers occurred on Sundays. This seems to have a logical explanation, given that the Sundays are the 2nd days of each week where most of the news that took place on Saturdays are published on Sundays' daily papers. Saturdays' events will be a collection of full and detailed coverage off all those events and news during the weekend. Thursday and Friday are the off-days therefore, it is natural that achievements would be very low to report to newspapers, and that is the reason why Thursdays' and Fridays' news coverage is very scant - Wednesday is the last work day of the week i.e. the day immediately before the weekend so most of the lengthy coverage and week backlog would be published on this day.

Press coverage of youth related issues per the "Journalistic Aspect" variable.

It is clear that news share of total youth related issues press coverage accounting for approximately $65 \%$. Which is a good thing. However, that was at the expense of other journalism aspects combined, with the exception of the journalistic reporting approximately $22 \%$ coverage, accounted for about $13 \%$ of the coverage. This clearly revealed the newspapers (writers and thinkers) drawback with regard to paying due attention and concern to writing 
and reporting youth related issues in their articles, as the article is considered one of the most important aspects in journalism that has positive impact on people by giving them the required recommended steps and guidance; in addition to analyzing the vital issues by showing their pros and cons. This will contribute to the Saudi youth development. If we focus on the 361 articles published during the study period, we will find that the 6 out of the 12 daily papers under study had an article addressing a youth issue on daily basis whereas none of the other 6 daily papers had had a single youth related article in the time span of the study (2 months).

- Press coverage of youth related issues per the "length of the issue" variable.

It is clear that there is a relative balancing in tackling youth related issues as far as the issue length is concerned, taking into consideration the importance of elaboration in dealing with such issues. It is not enough that long issues constitute $25 \%$ only - it should be more at the expense of short articles in the 1 st place and the medium length issue in the 2 nd place.

- Press coverage of youth related issues per the "General Topic" variable.

The focus on issues concerning "Education and Training" topic is clearly in the 1st place, followed by "security and politics" which shows the media awareness of the pillars of sustainable human resources, hence direct coverage thereof. Education, training and employment constitute one of the main aspects of the National Youth Strategy prepared by the Ministry of Economy \& Planning. As for the security and political aspect, it is considered the cornerstone of development - no development without security and no development without political awareness on all fronts; direct assistance from the political leadership is required. That is why these 3 aspects have come in the forefronts of the press coverage list. Whereas the other 3 aspect of the National Youth Strategy - Culture \& Information; IT, Communication and knowledge Society; and the Citizenship - were at the bottom of the press coverage list. Even then these 3 aspects were considered of great importance to achieve the hoped-for development. The world is continuously developing particularly in the area of technology. The new media machine is considered one of the most useful machines in guiding people towards their aim - up skilling and developing good citizen personality traits. The aforementioned 3 aspects constitute the actual entrance to Knowledge society and knowledge economy aimed at by all developing countries to reach the developed countries level. However, the percentage of the 3 aspects combined is $15.62 \%$ of the press coverage of the youth related issues.

- Press coverage of youth related issues per the "Opportunities \& Threats" variable

It is clear that with the exception of the "not applicable" category, opportunities indicators relating to the youth has the highest share of the press coverage. It is clearly noticed when you look at the Saudi daily papers covering the new projects that involve youth related potential job opportunities whether starting with training or direct employment and even extending towards educational opportunities ...etc. youth as an important category (15-29 years) are considered the essential part of the future development of the Kingdom of Saudi Arabia as is the case elsewhere in the world. So the coverage of the youth related opportunities and threats is proportionate with their importance in today's and future development. This point may even need more focus.

Study Finding:

- Press coverage of youth related issues based on each week day.

\begin{tabular}{lll}
\multicolumn{3}{l}{ TABLE I: YOUTH RELATED ISSUES PRESS COVERAGE BY DAY OF THE WEEK } \\
\hline \hline Day of the week & Frequency & $\%$ \\
\hline Sunday & 773 & 17.12 \\
Wednesday & 768 & 17.01 \\
Saturday & 716 & 15.86 \\
Thursday & 654 & 14.49 \\
Monday & 633 & 14.02 \\
Thursday & 517 & 11.45 \\
Friday & 453 & 10.04 \\
Total (N=4514) & 4514 & \\
\hline
\end{tabular}

This Table I indicates the frequency and percentage of the press coverage of the youth related issues based on each day of the week. The findings were:

- Sunday coverage was on the top of the list with 773 issues covered with a percentage of $17.12 \%$ of all issues covered.

- Wednesday has come on the 2 nd place with 768 issues and $17.01 \%$

- Friday coverage was the poorest with only 453 issues covered constituting $10.04 \%$.

- Thursday coverage was on the next from the bottom place with 517 issues and $11.45 \%$.

Fig. 1 shows youth related issues press coverage by day of the week.

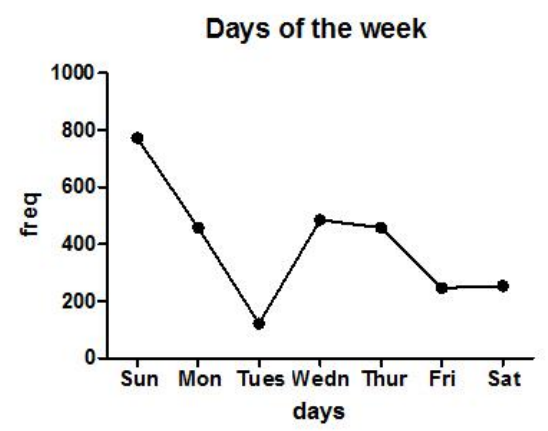

Fig. 1. Youth related issues press coverage by day of the week.

- Press coverage of youth related issues based on aspect of journalism used.

TABLE II: YOUTH RELATED ISSUES PRESS COVERAGE BY ASPECT OF JOURNALISM

\begin{tabular}{lll}
\hline \hline Aspect & Frequency & $\%$ \\
\hline News & 2926 & 64.82 \\
Journalistic report & 990 & 21.93 \\
Article & 361 & 8.00 \\
Interview & 196 & 4.34 \\
Advertisement & 41 & 0.91 \\
Total $(N=4514)$ & 4514 & \\
\hline \hline
\end{tabular}

Table II shows that youth related issues press coverage based on aspect of journalism resulted in the following findings: 
- News was on the top of the journalistic aspects list with 2926 frequencies and $64.82 \%$.

- Journalistic interview reports came 2nd with 990 frequencies and $21.93 \%$.

- Articles in the 3rd place with 361 issues and $8.00 \%$ only.

Fig. 2 shows youth related issues press coverage by aspect of journalism

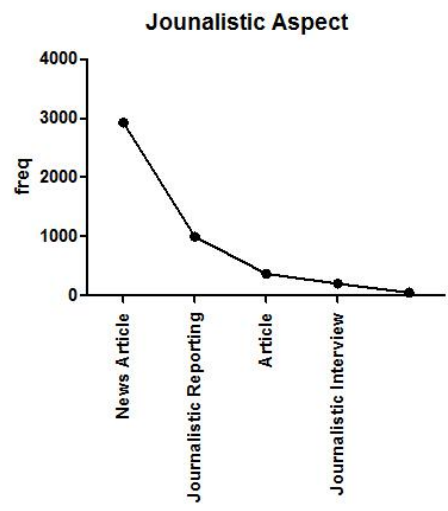

Fig. 2. Youth related issues press coverage by aspect of journalism.

- Press coverage of youth related issues by the size of the issue covered.

TABLE III: YouTH RELATED ISSUES PRESS COVERAGE BY SIZE OF ISSUE

\begin{tabular}{lll}
\hline \hline Issue Size & Frequency & $\%$ \\
\hline Small & 1794 & 39.74 \\
Medium & 1569 & 34.76 \\
Big & 1151 & 25.50 \\
Total $(N=4514)$ & 4514 & \\
\hline \hline
\end{tabular}

The above Table III indicated that the press coverage of the youth-related issues based on the issue length variable. findings were:

- The small size issues came $1^{\text {st }}$ with 1794 issue coverage with $39.74 \%$.

- Medium size issues followed with 1569 issue and $34.76 \%$

- Finally the big size issues covered were 1151 with $25.50 \%$

Fig. 3 shows youth related issues press coverage by size of issue.

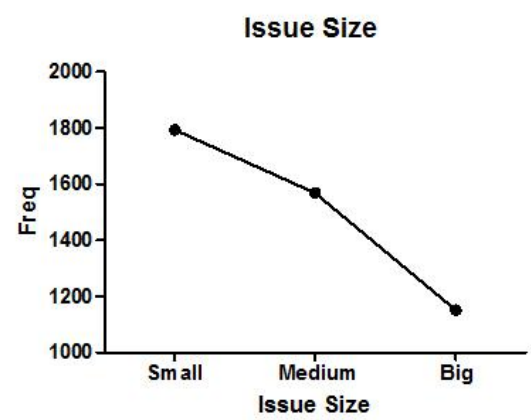

Fig. 3. Youth related issues press coverage by size of issue.

- Press coverage of youth related issues based on the general topic.
TABLE IV: YOUTH RELATED ISSUES PRESS COVERAGE BY GENERAL TOPIC NATURE

\begin{tabular}{lll}
\hline \hline General Topic Nature & Frequency & $\%$ \\
\hline Education \& Training & 968 & 21.44 \\
Employment & 771 & 17.08 \\
Security \& Political & 683 & 15.13 \\
Social & 504 & 11.17 \\
Health & 444 & 9.84 \\
$\begin{array}{l}\text { Recreational Activities \& Best use of } \\
\text { Leisure Time }\end{array}$ & 439 & \\
Citizenship & & \\
IT, Communication \& Knowledge & 248 & 9.72 \\
Society & 245 & 5.49 \\
Culture \& Information & & \\
Total $(N=4514)$ & 212 & 5.43 \\
\hline \hline
\end{tabular}

The above Table IV revealed that the youth related press coverage based on general topic variable. Findings were as follows:

- Education \& Training general topics was on the top of the list covering 968 issues with $21.44 \%$.

- Employment topics covering 771 issues with $17.08 \%$.

- The security and political general topic was on the $3 \mathrm{rd}$ place with 683 issues with $15.13 \%$.

- Regarding the culture and information topic, it has come last with 212 issues covered with $4.70 \%$.

- The IT, Communication and the Knowledge Society was 2 nd from the bottom with 245 issues covered of $5.43 \%$.

- With almost the same percentage $(5.49 \%)$ the general topic of citizenship came on the 7th place with 248 issues covered comprising $5.49 \%$ of the total issues covered.

Fig. 4 shows youth related issues press coverage by general topic nature.

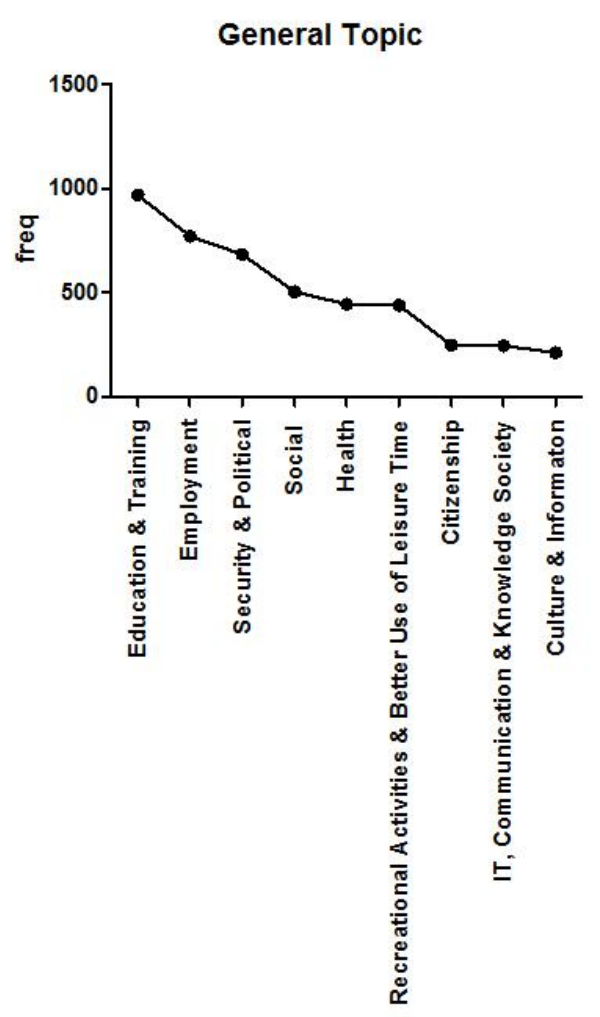

Fig. 4. Youth related issues press coverage by general topic nature. 
- Press coverage of youth related issues (Opportunities \& Threats)

TABLE V: Youth RELATED ISSUES PRESS COVERAGE By OPPORTUNITIES

\begin{tabular}{lll}
\multicolumn{3}{c}{ AND THREATS } \\
\hline \hline (Opportunities \& Threats) & Frequency & $\%$ \\
\hline Opportunities & 442 & 9.79 \\
Threats & 206 & 4.56 \\
Inapplicable & 3866 & 85.65 \\
Total $(N=4514)$ & 4514 & \\
\hline \hline
\end{tabular}

The above Table $\mathrm{V}$ showed the youth related issues coverage based on opportunities and threats. Findings were as follows:

- The inapplicable issues i.e. "that cannot be classified as opportunities nor threats" were on the top of the list with 3866 issues covered amounting to $85.65 \%$.

- Youth related opportunities issues came 2nd with 442 issue constituting $9.79 \%$ of the total issues covered.

Youth related Threats (and crises) issues came 3rd with 206 issues and $4.56 \%$.

Fig. 5 shows youth related issues press coverage by opportunities \& threats.

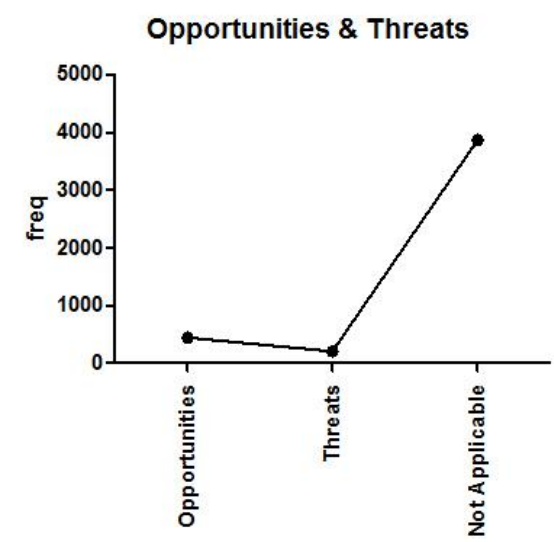

Fig. 5. Youth related issues press coverage by opportunities \& threats.

\section{DISCUSSION AND CONCLUSION}

\section{A. Findings}

(4514) youth related issues were monitored and analyzed. These issues were monitored in 12 Saudi daily papers published in Arabic Language through their websites Alriyadh (Riyadh), Aljazirah (Riyadh), Okaz (Jeddah), AlMadinah (AlMadinah), Alwatan (Abha), Alyaum (Dammam), Alnadwah (Makkah), AlBilad (Jeddah), Alsharq Alawsat (London), Aleqtisadiah, Shams and Alhayat (London).

Time span of 59 days - Month Rajab (7) and Shaa'ban (8) of 1432 of the Hijri Calendar.

Concentrated press coverage was noticed during Sundays and Wednesdays throughout the 2 month period.

The issues and subjects covered were classified into 5 major journalistic aspects - News, Investigative Reports, Articles, Interviews, and Advertisement with 64.82\%, $21.93 \%, 8.00 \% .4 .34 \%$ and $0.91 \%$ respectively from total issues covered.

Aspects were arranged in a descending order of the press coverage as follows: Education \& Training 21.44\%, employment 17.08 , security \& politics $15.13 \%$, Social $11.17 \%$, Health $9.84 \%$, recreational activities and best use of leisure time $9.72 \%$, citizenship $5.49 \%$, IT, Communication and Knowledge Society $5.43 \%$, and Culture \& information $4.70 \%$.

\section{B. Notes}

The Kingdom of the Saudi Arabia was able to effectively address the minor changes in the ideas of some few young people by introducing some fruitful promising economic measures offering more employment opportunities to young people, improving education and families' standard of living.

\section{ACKNOWLEDGEMENTS}

This work has been funded by the National Center for Youth Studies. Special thanks for those who contributed to the accomplishment of this study; namely: Eng. Basem M. Hboubati, Ahmed Y. AlHawamleh, Jamal El-Ddin A. Zaghloleh, Hassan S. ElSammani, Tarik J. Zaghloleh and Shakir AlHarbi.

\section{REFERENCES}

[1] Statistics and Information in the Ministry of Economy and Planning, of the Saudi Population and Housing Census released by the Central Department Of Statistics and Information, chapter 2, population and housing, pp. 5-12, 2009.

[2] R. Springborg. (September 2011). Whither the Arab Spring? 1989 or 1848 ? International Spectator. Routledge, part of the Taylor \& Francis Group. [Online]. 46(3). pp. 5-12. Available: http://www.ingentaconnect.com/content/routledg/is/2011/00000046/0 0000003/art00001

[3] S. Johnstone and J. Mazo. (April 2011). Global Warming and the Arab Spring. Survival: Global Politics and Strategy April-May - issue 2. [Online]. Available: http://www.iiss.org/en/publications/survival/sections/2011-2760/survi val--global-politics-and-strategy-april-may-2011-fbe8/53-2-03-johnst one-and-mazo-9254

[4] A. Parchami. (March 2012). The Arab Spring: the view from Tehran. Contemporary Politics. Routledge, part of the Taylor \& Francis Group. [Online]. $8(1) . \quad$ pp. 35-52. Available: http://www.ingentaconnect.com/content/routledg/ccpo/2012/0000001 8/00000001/art00008

[5] L. Roberts and J. Schostak. (May 2012). Obama and the 'Arab Spring': desire, hope and the manufacture of disappointment. Implications for a transformative pedagogy. Dangerous spaces: Threatening Sites for Social Justice. [Online]. 33(3). Available: http://www.tandfonline.com/doi/abs/10.1080/01596306.2012.681898 \#.UtumYPSm1Fk

[6] R. Aliboni. (Jan 2012).The International Dimension of the Arab Spring. The International Spectator: Italian Journal of International Affairs. [Online]. 46(4). Available: http://www.tandfonline.com/doi/abs/10.1080/03932729.2011.637712 \#.Utuj8fSm1Fk

[7] R. Dajani. (January 2011). What the Arab Spring Means for Science in the Arab World. Forbes. [Online]. Available: http://www.forbes.com/sites/johnfarrell/2011/09/01/what-the-arab-spr ing-means-for-science-in-the-arab-world/

[8] E. Murphy. (2012). Problematizing Arab Youth: Generational Narratives of Systemic Failure. Mediterranean Politics. [Online]. 17 (1). pp. 5-22. Available: https://www.dur.ac.uk/sgia/profiles/?mode $=$ pdetail $\&$ id $=490 \&$ sid $=490$ \&pdetail $=77667$

[9] N. Layadi, "The blogs and journalism: Changing the perspective to clarify the knowledge horizon," Arab Journal of Information and Communication, 1430AH, 5th issue.

[10] M. Alseweed, "University journalism in the kingdom of Saudi Arabia," M.S. thesis, Mass Communication \& Media College, Imam Muhammad Ibn Saud Islamic University, Riyadh, the Kingdom of Saudi Arabia, 1992.

[11] A. AlRifae, "Bases and principles of evaluating and motivating journalists in the Kingdom of Saudi Arabia," 1996, Dar AlMie'raj International Publishing, Riyadh. 
[12] M. AlSeweed, "Trends and attitudes of Saudi University students towards advertisement in university newspapers," Arab Journal of Information and Communication, 1430AH, 5th issue.

[13] S. Bakheet, "Modern trends and attitudes in journalism researches a survey and critical review of the predominant trends in journalism study," Arab Journal of Information and Communication, issue 6, pp. $57-169,2010$

[14] T. AlAhmedi, "An evaluation study regarding the survey of University Students' opinions with regard to the press coverage of the Saudi daily papers of the youth issues," An-Najah University Journal for Research - B (Humanities), issue 1, pp. 35-78, Palestine, 2006.

[15] F. Salamah, "The role of the Egyptian press in raising the Egyptian adolescents' awareness about the political reform issues," Journal of Childhood Studies, Egypt, vol. 13, issue 48, pp. 331-332, 2010.

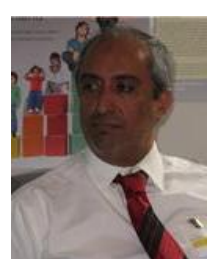

Nizar H. Alsalih was born in Saudi Arabia, in1959. He worked as the secretary-general of the National Center for Youth Studies since 2010, also He is a faculty member in the Department of Psychology, King Saud University since 1998. He got my doctorate in Psychology, Psychology Specialization growth, from University of Birmingham, UK, 1998. He delivered several classes in KSU, such as, developmental psychology, Childhood and related issues, developmental psychology, adolescence, and teaching social psychology. He achieved deferent certificates in coaching, for instance an international professional certification in critical thinking skills are supported from the center of strategic planning simplified, USA, Dubai, 2011, also Certified professional coach in international strategic planning approved by the Center for Strategic Planning simplified, USA, Dubai, 2011, and Certificate of Participation in the workshop of strategic planning for non-profit organizations, Amman,

\section{7-29/7/2010}

Finally, he published several articles, and he had worked experiences, such as, assistant secretary-general of the National Center for Youth Research, 2007-2010, member of the Standing Committee for Drug Control at the Ministry of Higher Education, since 2010, head of the scientific team to study the phenomenon of youth travel, 2009, member of the Advisory Committee for Combating Drugs, 2003-2008.

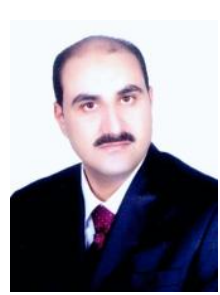

Kadhem A. Al Ghoul was born in Jordanian, in 1977. He worked as a supervisor unit of Studies, Research and Opinion Polls, at the National Center for Youth studies, at King Saud University, since May 2010 till now. 1977. He had a B.A English literature, Jerash private University in 2000, Jordan, he had M.S educational administration, Yarmouk University, Jordan, 2003, also he had a Ph.D. of educational administration, Yarmouk University, Jordan, 2006. His specialization is reform and development of administrative and educationa sector.

He worked as the manager unit of Studies and Research at Asbar Center for Studies, Research and communication, KSA, since December 2006 until January of 2010.

He participated in many researches, 1) Education right and opportunities for formation knowledge capital among youth in the Arab Spring countries, 2013. 2) The degree of satisfaction of students on the premises and secondary school facilities, 2013. 3) Values among Saudi youth between belief and practice, 2012, as a second author.

He owns membership of Arab Association for Responsible Media, and Trophy Al Hekmah channel for Scientific Achievements and Development in the Service of Society, Cairo, since April 29, 2011 